\title{
MORFORMETRIAE DESENVOLVIMENTO GONADAL EM (OREOCHROMIS NILOTICUS) SUPLEMENTADA COM VITAMINA E
}

\author{
MORPHOMETRY AND DEVELOPMENT OF GONAD IN (OREOCHROMIS NILOTICUS) \\ WITH SUPPLEMENTATION OF VITAMINE
}

\author{
Navarro, R.D. ${ }^{1}$, Matta, S.L.P. ${ }^{2}$, Ribeiro Filho, O.P. ${ }^{3}$, Ferreira, W.M. ${ }^{4}$, Miranda, D.C. ${ }^{5}$ \\ e Pereira, F.K.S. ${ }^{6}$
}

\begin{abstract}
${ }^{1}$ Universidade Federal de Minas Gerais. Brasil. rddnavarro@yahoo.com.br ${ }^{2}$ Departamento de Biologia Geral. Universidade Federal de Viçosa. Brasil. ${ }^{3}$ Departamento de Biologia Animal. Universidade Federal de Viçosa. Brasil. ${ }^{4}$ Departamento de Zootecnia. Escola de veterinária. Universidade Federal de Minas Gerais. Caixa Postal 567. CEP 30123-970. Belo Horizonte-MG. Brasil.

5Universidade Federal de Viçosa. Viçosa. Minas Gerais. Brasil.

6Universidade Federal de Lavras. Lavras. Minas Gerais. Brasil.
\end{abstract}

\section{PalaVRas ChaVE ADICIONAIS}

Tilapia do Nilo. Nutrição de peixes.

\section{RESUMO}

Objetivou-se avaliar o efeito da suplementação de vitamina E na morfometria e no desenvolvimento gonadal de tilápia (Oreochromis niloticus). Para peso da gônada, índice gonadossomático (IGS), espessura do testículo e porcentagem de lúmen foram observadas diferenças para tratamento $150 \mathrm{mg} / \mathrm{kg}$ de vitamina E. Para epitélio germinativo foi observada diferença para o tratamento com $150 \mathrm{mg}$ e para porcentagem de células de Leydig do tratamento com $50 \mathrm{mg}$ de vitamina E por kg. Para vasos sanguíneos foi maior com 50 e $150 \mathrm{mg}$. A exigência de vitamina $E$ para desenvolvimento gonadal da tilápia é de $150 \mathrm{mg} / \mathrm{kg}$.

\section{SUMMARY}

This study aimed to evaluate the effect of vitamin E supplementation in the morphometry and gonadal development of Nile tilapia (Oreochromis niloticus). Considering the weight of the gonad, gonadossomatic index, testes thickness and lumen percentage, significant differences were observed for the treatment with $150 \mathrm{mg} / \mathrm{kg}$ of vitamin $\mathrm{E}$. There were observed significant differences for percentage of germinative epithelium to $150 \mathrm{mg} / \mathrm{kg}$ of vitamin $\mathrm{E}$ and for percentage of Leydig cells in treatment with $50 \mathrm{mg} /$

Recibido: 17-11-08. Aceptado: 4-2-09.

\section{AdDitionAL KEYWORDS \\ Nile tilapia. Nutrition of fish.}

$\mathrm{kg}$ of vitamin $\mathrm{E}$. The percentage of blood vessels was higher in both treatments with 50 and $150 \mathrm{mg}$. The vitamin E requirement for gonadal development of tilápia is $150 \mathrm{mg} / \mathrm{kg}$.

\section{INTRODUÇÃO}

A tilápia Oreochromis niloticus, cuja carne é considerada de ótima qualidade, é o peixe mais importante do século XXI, sendo cultivado em mais de 100 países e também no Brasil devido sua rusticidade e rápido crescimento (Lovshin, 1997; Kubitza, 2000). O interesse pelo cultivo dessa espécie, no Sul e Sudoeste do país, cresceu rapidamente nos últimos oito anos em virtude da tecnologia de reversão sexual e da pesca esportiva representada pelos pesque-pague. A tilápia é criada em diversos sistemas, desde a cultura semi-intensiva em tanques que recebem dejetos animais, como em cultivos intensivos em raceways e tanquesrede (Kubitza, 2000).

O desenvolvimento eficiente e saudável dos animais passa obrigatoriamente pelo 
fornecimento de uma dieta que satisfaz as necessidades básicas de crescimento, contendo concentrações próximas do ideal e seus diversos componentes, aliados a tecnologia de preparação. A estocagem, a concentração de vitaminas e minerais, a biodisponibilidade dos nutrientes são exemplos de parâmetros que interferem no desenvolvimento do animal (Navarro et al., 2007).

A influência da dieta sobre o desempenho reprodutivo dos peixes permite a escolha de ingredientes em níveis mais adequados aos processos metabólicos do animal. Embora recentes estudos venham sendo conduzidos nessa linha, para melhorar o aproveitamento do potencial da piscicultura, poucos trabalhos relacionam nutrição e parâmetros reprodutivos (Luquet e Watanabe, 1986; Fernández-Palacios et al., 1995; Fernández-Palacios et al., 1997; Navarro et al., 2006).

$\mathrm{O} \alpha$-tocoferol é o representante mais importante do grupo de substância com atividade de vitamina E. Apresenta maior atividade biológica quando comparado aos demais compostos, devido ao maior índice de absorção intestinal, maior deposição nos tecidos, menor excreção fecal, além de ser oxidado mais lentamente (Barreto, 1998; Sampaio et al., 2004).

A vitamina E exerce algumas funções no organismo animal atuando como mais importante antioxidante metabólico presente nas membranas celulares, protegendo-a da oxidação de ácidos graxos e do colesterol, além de diminuir ou inibir a produção e a ação dos radicais livres (Guerra et al., 2004; Navarro et al., 2009). Sabe-se que a vitamina E atua nos ácidos graxos insaturados presentes nas membranas celulares e nas partículas subcelulares, evitando suas oxidações. Como antioxidante celular, a vitamina E intervém na estabilização dos ácidos graxos poliinsaturados da fração lipídica das membranas celulares. Assim, evita a formação de lipoperóxidos tóxicos, impedindo a formação de lesão nos vasos sangüíneos e alteração na permeabilidade capilar (Barreto, 1998).

Outros efeitos da vitamina E no desenvolvimento das gônadas, na fecundidade, na qualidade de ovos e sobrevivência de larvas foram estudados por FernándezPalacios et al. (1998); Izquierdo et al. (2001).

Além disso, poucas informações têm referenciado a morfometria e o desenvolvimento gonadal relacionado com a vitamina E. Nesse sentido objetivou-se avaliar o efeito da vitamina $\mathrm{E}$ na morfometria e no desenvolvimento gonadal de tilápias (Oreochromis niloticus).

\section{MATERIAL E MÉTODOS}

O experimento foi realizado no ranário experimental do Departamento de Biologia Animal - UFV - no período de 09/01/2005 a 25/04/2005, no total de 106 dias.

Foram utilizadas 400 tilápias revertidas (Oreochromis niloticus), provenientes de uma empresa que produz alevinos, com peso e comprimento inicial de $1,40 \pm 0,88 \mathrm{~g} \mathrm{e} 4,77 \pm$ $0,37 \mathrm{~cm}$, respectivamente. As pós-larvas foram distribuídas em 20 aquários com capacidade de 10001 cada, com renovação de água constante $7,5 \mathrm{ml} /$ minuto. O experimento de desempenho foi montado segundo um delineamento inteiramente ao acaso com cinco tratamentos $(0,50,100,150$ e 200 $\mathrm{mg} / \mathrm{kg}$ de vitamina $\mathrm{E}$ monofosfato - D $\alpha$ tocoferol) numa ração isoprotéica de $36 \%$ de $\mathrm{PB}$ e isocalórica $3600 \mathrm{kcal}$ de $\mathrm{ED} / \mathrm{kg}$ com quatro repetições (tabela I). A fase de adaptação foi de cinco dias.

As dietas experimentais foram peletizadas, secas em estufa de circulação forçada a $55^{\circ} \mathrm{C}$ e, posteriormente, fracionadas nos diâmetros de $1 \mathrm{~mm}$, entre $4 \mathrm{~mm}$ a $6 \mathrm{~mm}$, sendo utilizadas de acordo com o tamanho dos peixes. As dietas permaneceram armazenadas a $-20^{\circ} \mathrm{C}$ até sua utilização. As dietas experimentais foram peletizadas, e a oferta de ração foi de $5 \%$ do peso vivo, sendo ajustada a cada 15 dias. Foram realizadas despescas com de rede de malha de $3 \mathrm{~cm}$ 
Tabela I. Composições percentuais, químicas e calculadas das dietas experimentais. (Percentage and chemical composition of experimental diets as fed).

\begin{tabular}{|c|c|c|c|c|c|}
\hline \multirow[b]{2}{*}{ Ingrediente (\%) } & \multicolumn{5}{|c|}{ Dietas vitamina E mg/kg } \\
\hline & 0 & 50 & 100 & 150 & 200 \\
\hline Farelo de soja & 21,50 & 21,50 & 21,50 & 21,50 & 21,50 \\
\hline Glúten de milho & 30,00 & 30,00 & 30,00 & 30,00 & 30,00 \\
\hline Milho & 28,50 & 28,50 & 28,50 & 28,50 & 28,50 \\
\hline Farinha de peixe & 9,00 & 9,00 & 9,00 & 9,00 & 9,00 \\
\hline Óleo de soja & 7,60 & 7,60 & 7,60 & 7,60 & 7,60 \\
\hline Fosfato Bicálcio & 1,37 & 1,37 & 1,37 & 1,37 & 1,37 \\
\hline Calcário & 0,51 & 0,51 & 0,51 & 0,51 & 0,51 \\
\hline Sal & 0,40 & 0,40 & 0,40 & 0,40 & 0,40 \\
\hline Premix vitamínico e mineral $^{3}$ & 0,60 & 0,60 & 0,60 & 0,60 & 0,60 \\
\hline Metionina & 0,34 & 0,34 & 0,34 & 0,34 & 0,34 \\
\hline Lisina & 0,15 & 0,15 & 0,15 & 0,15 & 0,15 \\
\hline BHT (antioxidante) & 0,02 & 0,02 & 0,02 & 0,02 & 0,02 \\
\hline Vitamina E mg/kg & 0 & 50 & 100 & 150 & 200 \\
\hline \multicolumn{6}{|l|}{ Composição calculada } \\
\hline Proteína bruta ${ }^{1}(\%)$ & 36 & 36 & 36 & 36 & 36 \\
\hline Energia digestível $^{2}(\mathrm{kcal} / \mathrm{kg})$ & 3600 & 3600 & 3600 & 3600 & 3600 \\
\hline Fibra bruta ${ }^{1}(\%)$ & 2,30 & 2,30 & 2,30 & 2,30 & 2,30 \\
\hline Lisina $(\%)$ & 1,50 & 1,50 & 1,50 & 1,50 & 1,500 \\
\hline Metionina + Cistina (\%) & 1,11 & 1,11 & 1,11 & 1,11 & 1,11 \\
\hline Treonina (\%) & 1,35 & 1,35 & 1,35 & 1,35 & 1,35 \\
\hline Triptófano (\%) & 0,29 & 0,29 & 0,29 & 0,29 & 0,29 \\
\hline Cálcio (\%) & 1,04 & 1,04 & 1,04 & 1,04 & 1,04 \\
\hline Fósforo total² (\%) & 0,8 & 0,8 & 0,8 & 0,8 & 0,8 \\
\hline RelaçãoED:PB & 10 & 10 & 10 & 10 & 10 \\
\hline
\end{tabular}

${ }^{1}$ Com base nas análises de laboratório LNA/DZO.

${ }^{2}$ Baseados nos valores propostos pelo NRC (1993) e por Rostagno et al. (2000).

${ }^{3}$ Premix vitamínico comercial (5 kg/t), com níveis de garantia por quilograma de produto: Vit. A, 1200000 UI; Vit. $D_{3}$, 200000 UI; Vit. $K_{3}, 2400$ mg; Vit. $B_{3}, 4800$ mg; Vit. $B_{2}, 4800$ mg; Vit. B, 4000 mg; Vit. B 12,4800 mg; Ác. fólico, 1200 mg; pantotenato Ca 12000 mg; Vit. C, 48000 mg; biotina, 48 mg; Cloreto de colina, 108000 mg; Niacina, 24000 mg; e premix mineral comercial (1 kg/t), com níveis de garantia por quilograma do produto: Fe, 50000 mg; Cu, 3000 mg; Mn, 20000 mg; Zn, 3000 mg; I, 100 mg; Co, 10 mg; Se, 100 mg.

entre nós, sendo capturados $15 \%$ dos animais. As biometrias foram realizadas com auxílio de paquímetro e de balança de precisão. Os peixes foram alimentados três vezes ao dia (08:00; 13:00 e 18:00 horas). Os aquários foram sifonados diariamente para retirar sobras de ração e fezes. O fotoperíodo foi de 12 horas. A averiguação da temperatura da água foi realizada diariamente às 7 horas e às 17 horas, enquanto o pH, o oxigênio dissolvido e a amônia, foram aferidos a cada 7 dias.

Depois de 106 dias de experimento, 50 peixes foram separados ao acaso; dez animais de cada tratamento. No final do experimento, após jejum de 24 horas, os peixes foram abatidos por insensibilização (caixas isotérmicas com gelo moído e água 


\section{NAVARRO, MATTA, RIBEIRO FILHO, FERREIRA, MIRANDA E PEREIRA}

na proporção 1:1) de acordo com (Navarro et al., 2007). Depois do abate, foram eviscerados. O fígado e as gônadas foram retirados, pesados em balança de precisão $(0,001 \mathrm{~g})$ e mensuraram o comprimento e espessura com paquímetro. Um dos testículos foi selecionado e fixado em líquido Boiun. Esses fragmentos de testículos foram desidratados em séries alcoólicas crescentes e incluídos em resina polimerizável do tipo glicol metacrilato. Foram feitos cortes de 3 $\mu \mathrm{m}$ de espessura, em micrótomo ReichertJung Histocut 2045. As preparações obtidas foram coradas pelo azul de toluidina e borato de sódio (Matta et al., 2002, Navarro et al., 2006; Vilela, 2003).

A preparação histológica bem como as análises morfológicas e morfométricas foram realizadas no laboratório de Biologia Estrutural do Departamento de Biologia Geral da UFV.

No microscópio de luz, foi realizada com auxílio de uma ocular integradora dotada de 121 pontos, em aumento de 400 vezes, a avaliação da proporção volumétrica dos componentes do parênquima testicular. Pontos correspondentes a túbulo seminífero, intertubulo, vasos sangüíneos e linfáticos foram computados em vinte cam- pos aleatoriamente distribuídos para cada animal.

Para os parâmetros reprodutivos foi analisado o estádio de maturação gonadal, por meio de análise histológica, além do índice gonadossomático (IGS).

A relação entre o peso corporal e o peso das gônadas foi determinada para cada exemplar, utilizando-se a fórmula:

$$
I G S=P G / P C \times 100
$$

onde:

$P G=$ peso da gônada.

$\mathrm{PC}=$ peso corporal.

As análises estatísticas foram realizadas por meio do programa SAS (1997). Os efeitos da suplementação de vitamina $E$ foram analisados aplicando o teste de Duncan com $5 \%$ de probabilidade.

\section{RESULTADOS E DISCUSSÃO}

Valores médios obtidos de temperatura foi de $28,23 \pm 0,63 ; 7,25 \pm 0,58$ para $\mathrm{pH}$ $5,23 \pm 0,85 \mathrm{mg} \mathrm{l}^{-1}$ para oxigênio dissolvido. Permaneceram dentro das condições ótimas para crescimento da espécie de acordo com (Castagnolli, 1992).

Tabela II. Peso corporal (PC), comprimento total (CT), peso da gônada (PG), índice gonadossomático (IGS), comprimento da gonada (CG) e espessura do testículo (ET) de alevinos de tilápia revertida suplementadas com níveis de vitamina E. (Body weight (PC), total length (CT), weight of gonad (PG), gonadosomatic index (IGS), length of gonad (CG) and thickness of the testes (ET) of fingerlings of tilapia reversed supplemented with levels of vitamin E).

\begin{tabular}{lcccccc}
\hline Variáveis & 0 & 50 & 100 & 150 & 200 & C.V. \\
\hline PC $(\mathrm{g})$ & $74,04 \pm 5,3$ & $71,42 \pm 5,9$ & $73,87 \pm 6,22$ & $72,72 \pm 3,18$ & $72,52 \pm 4,47$ & 17,01 \\
CT $(\mathrm{cm})$ & $15,12 \pm 1,27^{\mathrm{b}}$ & $15,31 \pm 0,22^{\mathrm{b}}$ & $15,51 \pm 0,88^{\mathrm{ab}}$ & $15,86 \pm 0,48^{\mathrm{a}}$ & $15,85 \pm 0,36^{\mathrm{a}}$ & 7,82 \\
PG $(\mathrm{g})$ & $0,37 \pm 0,25^{\mathrm{b}}$ & $0,42 \pm 0,26^{\mathrm{b}}$ & $0,43 \pm 0,23^{\mathrm{b}}$ & $0,56 \pm 0,36^{\mathrm{a}}$ & $0,48 \pm 0,26^{\mathrm{ab}}$ & 59,00 \\
IGS $(\mathrm{g})$ & $0,51 \pm 0,40^{\mathrm{b}}$ & $0,60 \pm 0,41^{\mathrm{ab}}$ & $0,59 \pm 0,43^{\mathrm{ab}}$ & $0,77 \pm 0,56^{\mathrm{a}}$ & $0,70 \pm 0,48^{\mathrm{ab}}$ & 65,21 \\
CG $(\mathrm{cm})$ & $2,78 \pm 0,70$ & $2,66 \pm 0,55$ & $2,47 \pm 0,64$ & $2,57 \pm 0,53$ & $2,64 \pm 0,69$ & 24,10 \\
ET $(\mathrm{cm})$ & $0,41 \pm 0,17^{\mathrm{b}}$ & $0,42 \pm 0,11^{\mathrm{ab}}$ & $0,42 \pm 0,17^{\mathrm{ab}}$ & $0,50 \pm 0,16^{\mathrm{a}}$ & $0,45 \pm 0,18^{\mathrm{ab}}$ & 36,78 \\
\hline
\end{tabular}

Letras distintas indicam na mesma linha diferença significativa $(p<0,05)$ pelo teste de Duncan. Média \pm erro padrão; C.V.= coeficiente de variação.

Archivos de zootecnia vol. 59, núm. 228, p. 522. 
Os resultados de peso corporal (PC), de peso da gônada (PG), de comprimento total (CT), de comprimento padrão (CP), de índice gonadossomático (IGS), de comprimento da gônada (CT), de espessura do testículo (ET) são apresentados na (tabela II).

No presente experimento não foi observada diferença significativa $(\mathrm{p}>0,05)$ para peso corporal (tabela II). Para o comprimento total forma observadas diferenças significativas para os tratamento com 100, 150 e $200 \mathrm{mg}$ de vitamina $\mathrm{E} / \mathrm{kg}$ (tabela II).

Para peso da gônada foram observadas diferenças significativas $(p<0,05)$ com a suplementação de vitamina E de $150 \mathrm{mg}$ e $200 \mathrm{mg} / \mathrm{kg}$, resultado também observado para índice gonadossomático (IGS) (tabela II). É possível que esse aumento do peso da gônada e IGS sejam devido à função antioxidante que a vitamina $\mathrm{E}$ exerce sobre as células espermatogênicas. Esses resultados podem ser explicados pelos estudos de Fernández-Palacios et al. (1998) que observou que o aumento na suplementação de vitamina E melhorou a taxa de eclosão e porcentagem de larvas normais, devido, principalmente, a seu papel antioxidante. $\mathrm{O}$ peso testicular é diretamente relacionado com a produção espermática e, assim sendo, quanto maior o testículo maior a produção de espermatozóides, embora a quantidade de espermatozóides produzidos seja sempre

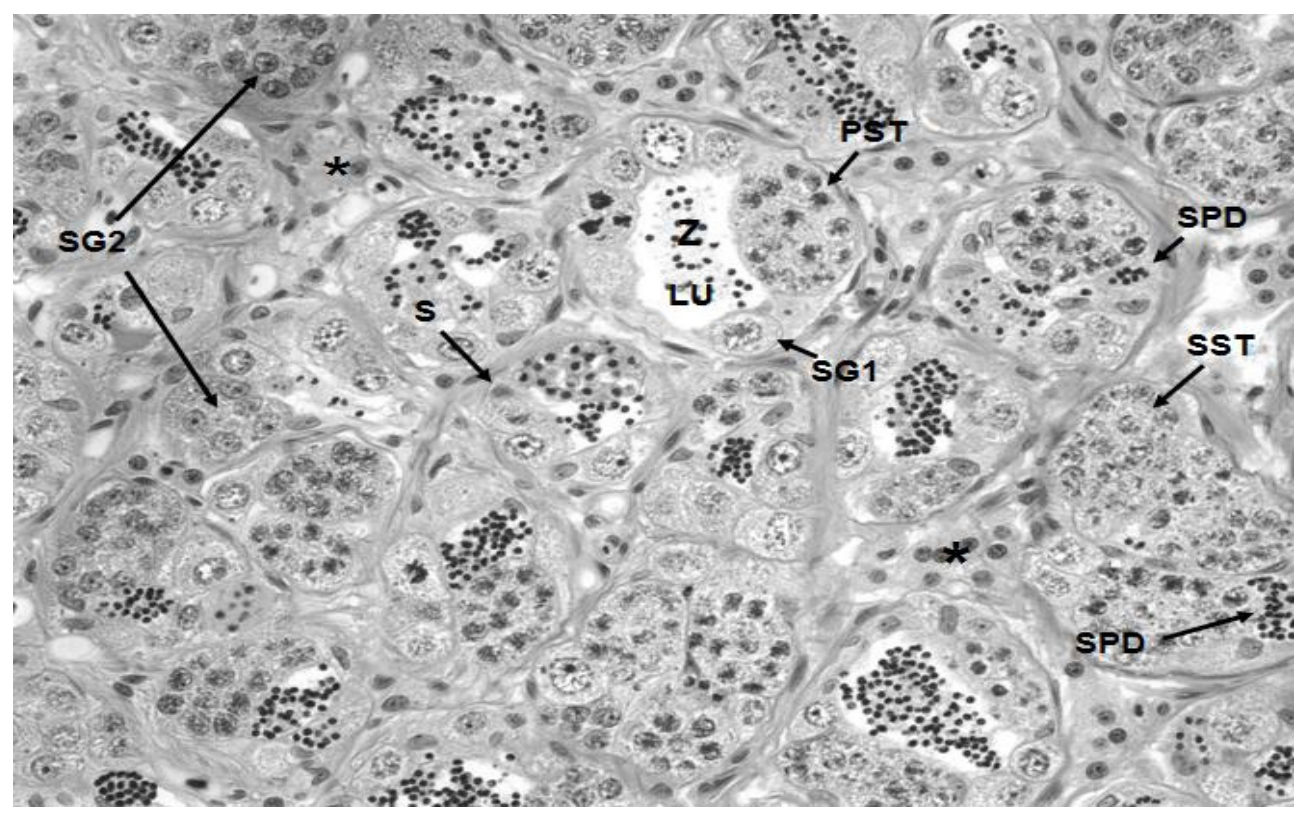

Figura 1. Fotomicrografia de testículo de tilápia nilótica que não recebeu suplementação de vitamina $E$ na dieta destacando a espermatogônia primária (SG1), espermatogônia secundária (SG2), espermatócito primário (PST), espermatócito secundária (SST), espermátides (SPD), lúmen (LU), espermatozóide (Z), células de Sertoli $(S)$, espaço intersticial (asterisco) do testículo. Azul de toluidina/borato de sódio 1\%. (Photomicrograph of testis of Nile tilapia what not receive supplementation of vitamin $\mathrm{E}$ in the diet emphasizing the primary spermatogonia (SG1), secondary spermatogonia (SG2), primary spermatocytes (PST), secondary spermatocytes (TSS), spermatids (SPD), lumen (LU), sperm (Z), Sertoli cells (S), interstitial space (asterisk) of the testis. Toluidine blue/sodium borate $1 \%)$. 


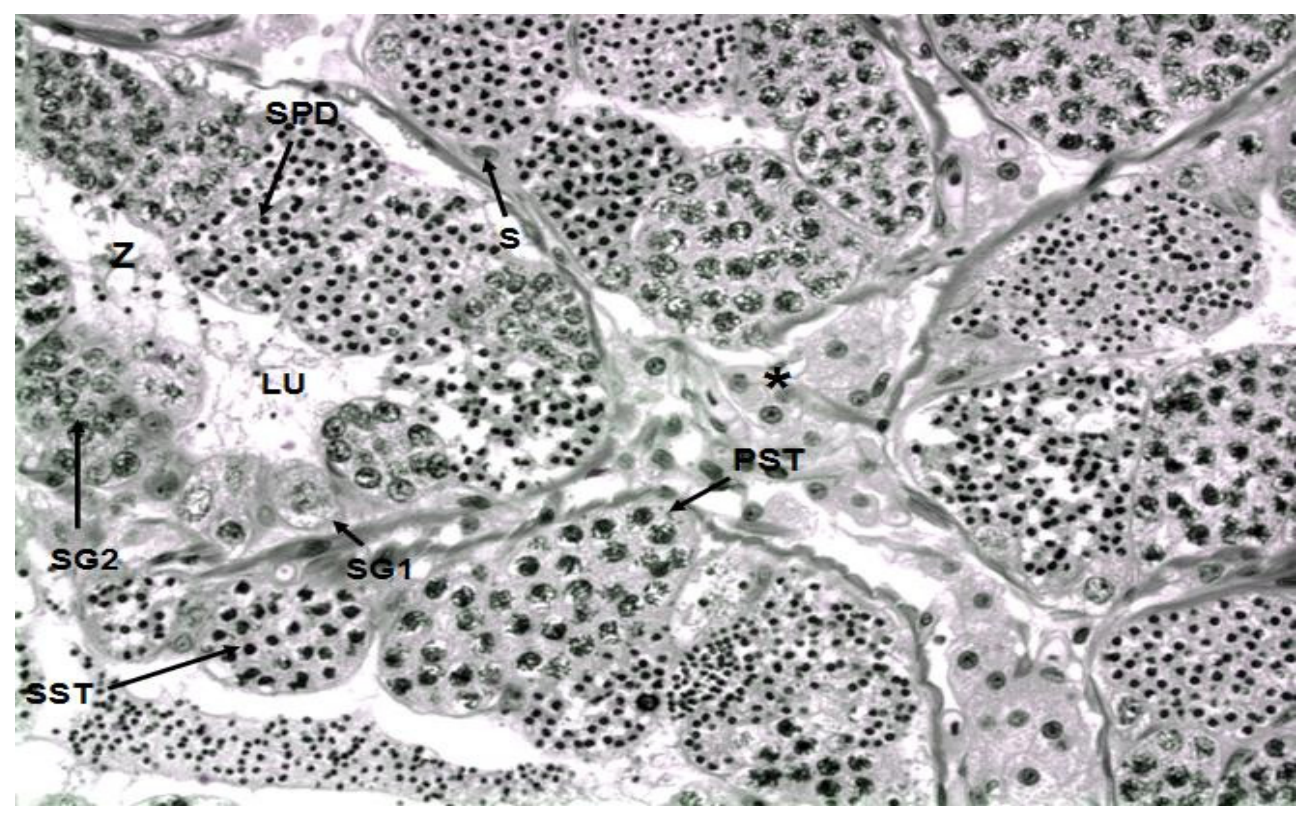

Figura 2. Fotomicrografia de testículo de tilápia nilótica que recebeu suplementação de 100 mg de vitamina E na dieta, destacando espermatogônia primária (SG1), espermatogônia secundária (SG2), espermatócito primário (PST), espermatócito secundária (SST), espermátides (SPD), lúmen (LU), espermatozóide (Z), células de Sertoli (S), espaço intersticial (asterisco) do testículo. Azul de toluidina/borato de sódio 1\%. (Photomicrograph of testis of Nile tilapia what received supplementation of $100 \mathrm{mg}$ vitamin $\mathrm{E}$ in the diet emphasizing the primary spermatogonia (SG1), secondary spermatogonia (SG2), primary spermatocytes (PST), secondary spermatocytes (TSS), spermatids (SPD), lumen (LU), sperm (Z), Sertoli cells (S), interstitial space (asterisk) of the testis. Toluidine blue/sodium borate $1 \%$ ).

maior que o número necessário para fecundação (França e Russell, 1998).

Outros autores como Gupta et al. (1987) observaram maior IGS utilizando suplementação de $270 \mathrm{mg}$ de vitamina E. Resultado semelhante a esse estudo foi observado por Tan e He (1998) ao constatarem maior IGS em Monopterus albus alimentados com $220 \mathrm{mg}$ de vitamina $\mathrm{E}$ por $\mathrm{kg}$ de dieta e relatarem que a suplementação de vitamina E melhora o desenvolvimento de gônadas. Guerra et al. (2004) relatam que a vitamina E ( $\alpha$-tocoferol e seus derivados), predominante antioxidante lipossolúvel animal, protege as células de radicais livres de oxigênio in vivo e in vitro. Para o comprimento do testículo não se observaram diferenças significativas $(p>0,05)$ ((tabela II). Para espessura do testículo foram observadas diferenças significativas $(\mathrm{p}<0,05)$ para o tratamento com suplementação de vitamina E de $50 \mathrm{mg}, 100 \mathrm{mg}, 150 \mathrm{mg}$ e $200 \mathrm{mg} / \mathrm{kg}$ (tabela II).

Na análise de microscopia das gônadas, observou-se um dinamismo no processo de espermatogênese, conforme descrito por Matta et al. (2002) na mesma espécie estudada no presente estudo. Para porcentagem de lúmen, houve aumento significativo $(\mathrm{p}<0,05)$ do tratamento com $150 \mathrm{mg}$ de vitamina E por kg de ração em relação aos demais tratamentos (tabela III e figura 3). 


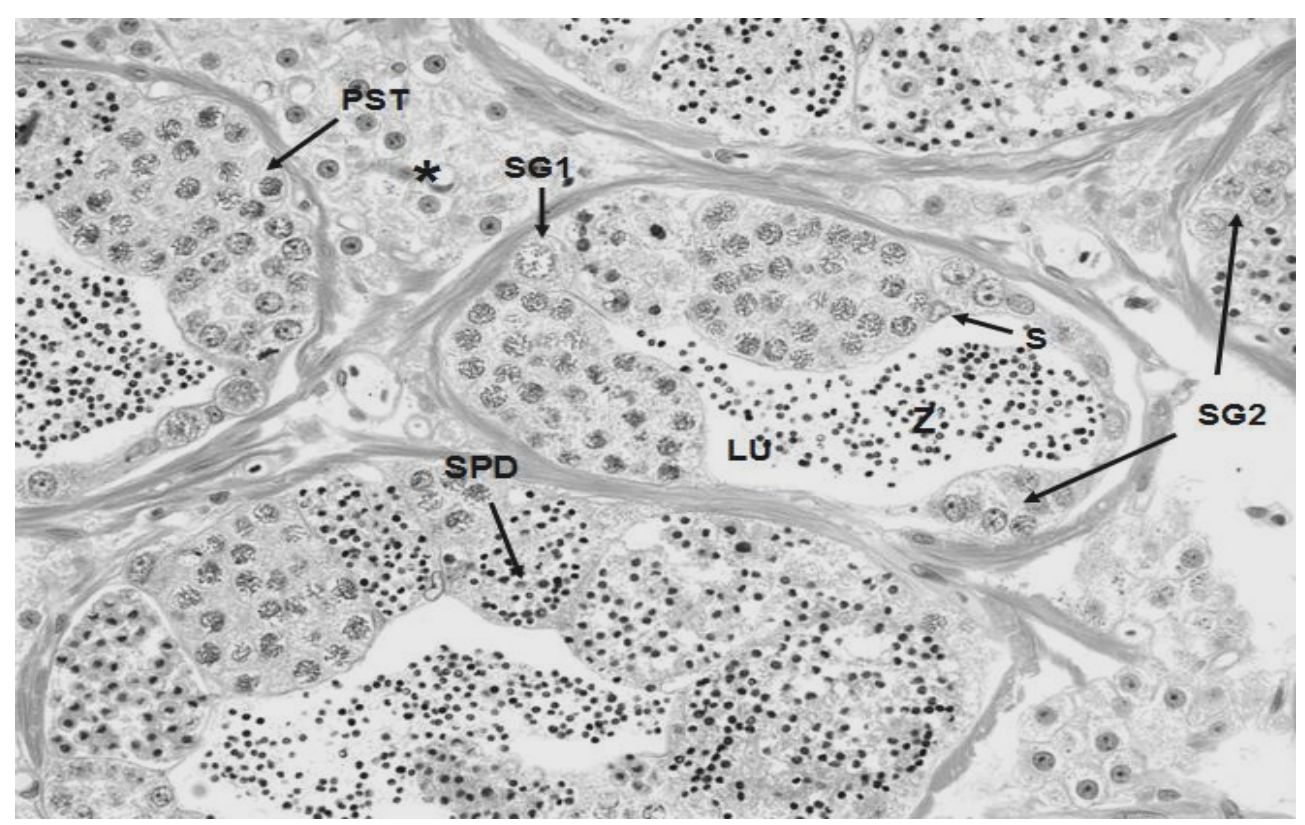

Figura 3. Fotomicrografia de testículo de tilápia nilótica que recebeu suplementação de 150 $m g$ de vitamina $E$ na dieta, destacando espermatogônia primária (SG1), espermatogônia secundária (SG2), espermatócito primário (PST), espermátides (SPD), lúmen (LU), espermatozóide (Z), células de Sertoli (S), espaço intersticial (asterisco) do testículo. Azul de toluidina/borato de sódio 1\%. (Photomicrograph of testis of Nile tilapia what received supplementation of $150 \mathrm{mg}$ vitamin $\mathrm{E}$ in the diet emphasizing the primary spermatogonia (SG1), secondary spermatogonia (SG2), primary spermatocytes (PST), secondary spermatocytes (TSS), spermatids (SPD), lumen (LU), sperm (Z), Sertoli cells (S), interstitial space (asterisk) of the testis. Toluidine blue/ sodium borate $1 \%)$.

Ao analisar a estrutura dos túbulos seminíferos e dos cistos de células germinativas, observou-se acentuada semelhança nos diferentes tratamentos (figuras 1 a 4). No entanto, nos peixes tratados com 100 mg e $150 \mathrm{mg}$ de vitamina E por $\mathrm{kg}$, os túbulos seminíferos apresentaram maior lúmen $(\mathrm{Lu})$ e, aparentemente, maior quantidade de espermatozóide $(Z)$ (figuras 2 e 3 ). Em relação à porcentagem de epitélio germinativo, foi observada diferença significati$\mathrm{va}(\mathrm{p}<0,05)$ para o tratamento de $150 \mathrm{mg}$ de vitamina $\mathrm{E}$ por $\mathrm{kg}$ em relação aos demais tratamentos (tabela III). Segundo Andriguetto (1983) a vitamina E possui fator antiesterilizante, essencial para a manu- tenção testicular, fazendo proteção do epitélio germinativo.

O compartimento intertubular do parênquima testicular é composto por vasos sanguíneos e linfáticos, por nervos, por células conjuntivas e por células de Leydig. A organização desses componentes pode seguir padrões distintos em diferentes espécies (Fawcett et al., 1973; Russel, 1996). As células de Leydig podem ocupar pequena porcentagem, cerca de $2 \%$ no rato (França e Russel, 1998), alcançando na capivara $60 \%$ (Paula, 1999). Sendo assim, a célula de Leydig é o elemento constituinte do compartimento intertubular que apresenta maior variação percentual entre as espécies já estudadas. 


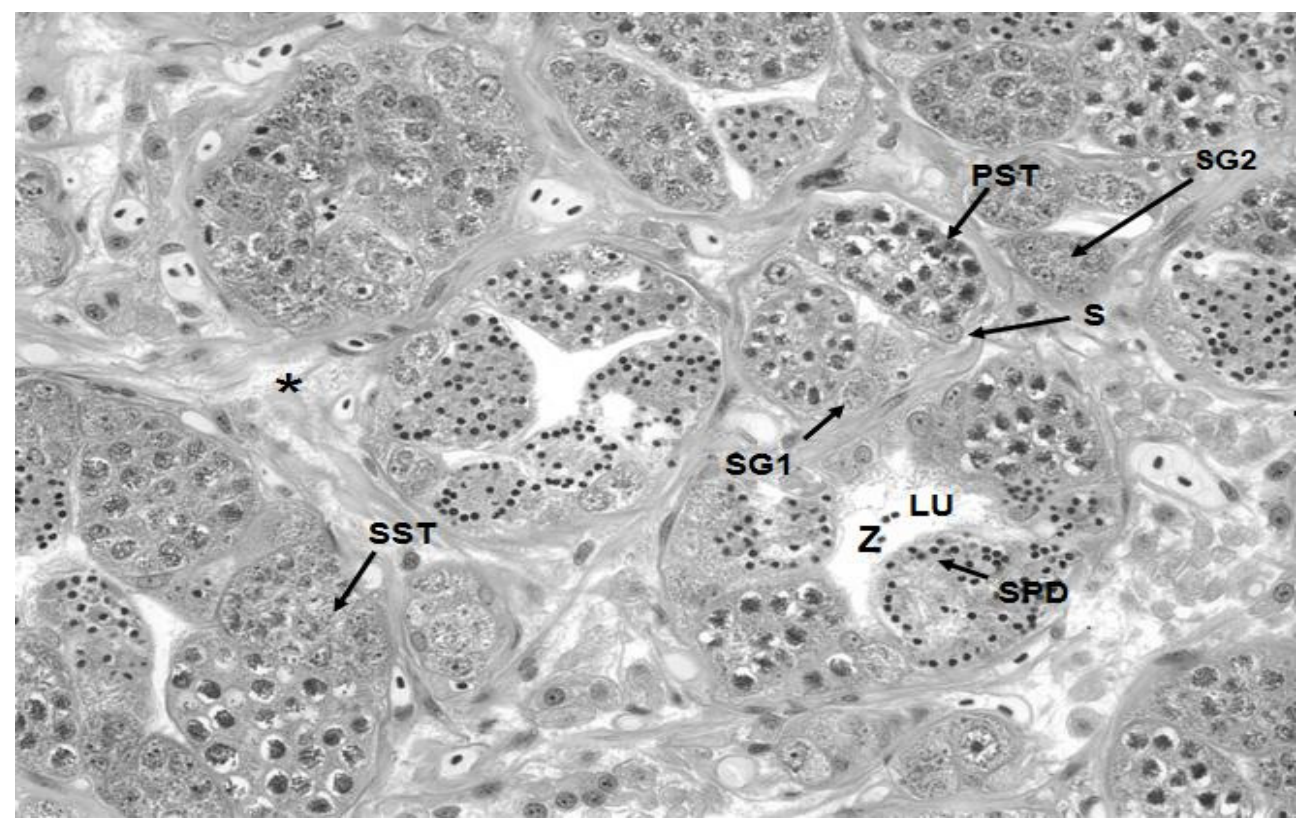

Figura 4. Fotomicrografia de testículo de tilápia nilótica que recebeu suplementação de $200 \mathrm{mg}$ de vitamina E na dieta, destacando espermatogônia primária (SG1), espermatogônia secundária (SG2), espermatócito primário (PST), espermatócito secundário (SST), espermátides (SPD), lúmen (LU), espermatozóide (Z), células de Sertoli (S), espaço intersticial (asterisco) do testículo. Azul de toluidina/borato de sódio 1\%. (Photomicrograph of testis of Nile tilapia what received supplementation of $200 \mathrm{mg}$ vitamin $\mathrm{E}$ in the diet emphasizing the primary spermatogonia (SG1), secondary spermatogonia (SG2), primary spermatocytes (PST), secondary spermatocytes (TSS), spermatids (SPD), lumen (LU), sperm (Z), Sertoli cells (S), interstitial space (asterisk) of the testis. Toluidine blue/sodium borate $1 \%$ ).

Vilela (2003) observou, em testículo de tilápia do Nilo que células de Leydig foram encontradas próximas ao ducto espermático, sugerindo relação funcional com o processo espermatogênico. Observou-se diferença significativa na porcentagem de célula de Leydig do tratamento com $50 \mathrm{mg}$ de vitamina $E$ por kg de ração em relação aos outros tratamentos (tabela III).

A porcentagem de vasos sanguíneos foi maior nos trata-mentos com $50 \mathrm{mg}$ e $150 \mathrm{mg}$ de vitamina E (tabela III). Essa diferença no percentual de vasos sanguíneos parece não interferir no processo espermatogênico, pois todos os animais analisados apresentaram padrão testicular normal.
Os espaços linfáticos ocupam cerca de $3,5 \%$ do parênquima testicular na maioria dos animais estudados (Russell et al., 1995). Em tilápias a porcentagem de vasos linfáticos não apresentou diferenças significativas (tabela III). Também não foram observadas diferenças significativas na porcentagem de túbulo e de intertúbulo ( $\mathrm{p}>0,05)$.

\section{CONCLUSÕES}

A suplementação com vitamina E (vitamina $\mathrm{E}$ monofosfato) é importante em dietas para desenvolvimento gonadal de tilápias revertidas, e a dose recomendada na ração é de $150 \mathrm{mg} / \mathrm{kg}$. Para porcentagem de célula 
Tabela III. Proporção volumétrica em porcentagem do testicular de tilápias revertidas alimentadas com dieta suplementada com níveis crescentes de vitamina E. (Share volumetrical in percentage, of testicular elements reversed tilapia fed with diet supplemented with increasing levels of vitamin E).

\begin{tabular}{lcccccr}
\hline & \multicolumn{5}{c}{ Vitamina E mg/kg } \\
Variaveis & 0 & 50 & 100 & 150 & 200 & C.V. \\
\hline Túbulo & $87,53 \pm 8,11^{\mathrm{a}}$ & $82,53 \pm 5,73^{\mathrm{a}}$ & $86,73 \pm 2,55^{\mathrm{a}}$ & $85,70 \pm 2,29^{\mathrm{a}}$ & $87,45 \pm 5,10^{\mathrm{a}}$ & 6,08 \\
Lúmen & $17,22 \pm 12,32^{\mathrm{b}}$ & $12,50 \pm 15,90^{\mathrm{b}}$ & $25,04 \pm 24,27^{\mathrm{ab}}$ & $30,84 \pm 9,88^{\mathrm{a}}$ & $17,34 \pm 17,33^{\mathrm{b}}$ & 75,34 \\
Epitélio germinativo & $70,31 \pm 17,09^{\mathrm{a}}$ & $70,03 \pm 16,81^{\mathrm{a}}$ & $61,69 \pm 24,61^{\mathrm{a}}$ & $54,86 \pm 12,19^{\mathrm{b}}$ & $70,11 \pm 20,64^{\mathrm{a}}$ & 25,65 \\
Intertúbulo & $12,47 \pm 6,97^{\mathrm{a}}$ & $17,47 \pm 5,73^{\mathrm{a}}$ & $13,27 \pm 2,5^{\mathrm{a}}$ & $14,30 \pm 2,29^{\mathrm{a}}$ & $12,55 \pm 5,10^{\mathrm{a}}$ & 37,50 \\
Célula de Leydig & $5,7 \pm 3,87^{\mathrm{b}}$ & $10,52 \pm 4,81^{\mathrm{a}}$ & $7,07 \pm 2,72^{\mathrm{b}}$ & $7,77 \pm 1,40^{\mathrm{b}}$ & $6,55 \pm 4,23^{\mathrm{b}}$ & 41,49 \\
Vaso linfático & $3,97 \pm 4,60^{\mathrm{a}}$ & $2,99 \pm 2,29^{\mathrm{a}}$ & $3,16 \pm 1,44^{\mathrm{a}}$ & $2,97 \pm 1,92^{\mathrm{a}}$ & $2,96 \pm 2,14^{\mathrm{a}}$ & 83,53 \\
Vaso sangüíneo & $2,8 \pm 0,60^{\mathrm{b}}$ & $3,96 \pm 1,20^{\mathrm{a}}$ & $3,04 \pm 0,92^{\mathrm{b}}$ & $3,56 \pm 0,97^{\mathrm{ab}}$ & $3,04 \pm 0,60^{\mathrm{b}}$ & 26,23 \\
\hline
\end{tabular}

Letras distintas indicam na mesma linha diferença significativa $(p<0,05)$ pelo teste de Duncan.

Média \pm erro padrão; C.V.= coeficiente de variação.

de Leydig a dose recomendada foi de $50 \mathrm{mg} /$ $\mathrm{kg}$. Essa dose de vitamina E, na dieta de

\section{BIBLIOGRAFIA}

Andriguetto, J.N. 1983. Nutrição animal. $5^{\mathrm{a}}$ ed. Editora Nobel. São Paulo. 395 pp.

Barreto, S.L.T. 1998. Niveis de proteina e vitamina E para matrizes de frangos de corte na fase de produção. (Tese de doutorado). Escola de Veterinária. Universidade Federal de Minas Gerais. Belo Horizonte. $171 \mathrm{pp}$.

Castagnolli, N. 1992. Piscicultura de água doce. FUNEP. Jaboticabal. 189 pp.

Fawcett, D.W., Neaves, W.B. and Flores, M.N. 1973. Comparative observations on intertubular lymphatic and the organization of the interstitial tissue of the mammalian testis. Biol. Reprod., 9: 500-532.

Fernández-Palacios, H., Izquierdo, M., Robaina, L., Valencia, A., Salhi, M. and Vergara, J. 1995. Effect of n3 HUFA level in broodstock diets on egg quality of gilthead seabream Sparus aurata L. Aquaculture, 32: 325-337.

Fernández-Palacios, H., Izquierdo, M., Robaina, L., Valencia, A., Salhi, M. and Montero, D. 1997. The effect of dietary protein and lipid from squid and fish meals on egg quality of broodstock for gilthead seabream (Sparus aurata). Aquaculture, 148: 213-246. tilápia, proporciona mais desenvolvimento reprodutivo.

Fernandez-Palacios, H., Izquierdo, M., Gonzalez, M., Robaina, L. and Valencia, A. 1998. Combined effect of dietary $\alpha$-tocopherol and ny3 HUFA on egg quality of gilthead seabream broodstock Sparus aurata. Aquaculture, 161: 475-476.

França, L.R. and Russell, L.D. 1998. The testis of domestic animals. In: Regadera, J., MartinezGarcia (eds.). Male reproduction. A multidisciplinary overview. Churchill Comunications. Madrid. pp. 197-219.

Guerra, M.M.P., Evans, G. e Maxwell, W.M.C. 2004. Papel de oxidantes e antioxidantes na andrologia: Revisão de literatura. Rev. Bras. Reprod. Anim., 28: 187-195.

Gupta, S.D., Khan, H.A. and Bhowmic, R.M. 1987. Observations on the effect of vitamin $E$ and growth hormone on the gonadal maturity of carps. J. Insland Fish. Soc. India, 19: 26-31.

Izquierdo, M.S., Fernandez-Palacios, H. and Tacon, A. 2001. Effect of broodstock nutrition on reproductive performance of fish. Aquaculture, 197: 25-42.

Kubitza, F. 2000. Tilápia: tecnologia e planejamento na produção comercial. $1^{a}$ ed. Editora Acqua 


\section{NAVARRO, MATTA, RIBEIRO FILHO, FERREIRA, MIRANDA E PEREIRA}

Supre Com. Suprim. Aqüicultura Ltda. Jundiaí, SP. 289 pp.

Lovshin, L.L. 1997. Tilapia farming: a growing worldwide aquaculture industry. In: I Simpósio Sobre Manejo e Nutrição de Peixes. 1997. Piracicaba, Anais... pp. 90-98.

Luquet, P. and Watanabe, T. 1986. Interaction "nutricion-reproduction" in fish. Fish Physiol. Biochem., 2: 121-129.

Matta, S.L.P., Vilela, D.A.R., Godinho, H.P. and França, L.R. 2002. The goitrogen 6-n-propyl-2thiouracil (PTU) given during testis development increases Sertoli and germ cell numbers per cyst in fish: The tilapia (Oreochromis niloticus) model. Endocrinology, 143: 970-978.

Navarro, R.D., Matta, S.L.P., Lanna, E.A.T., Donzele, J.L., Rodrigues, S.S., Silva, R.F., Calado, L.L. e Ribeiro Filho, O.P. 2006. Níveis de energia digestível na dieta de piauçu no desenvolvimento testicular em estágio póslarval. Zootec. Trop., 24: 153-163.

Navarro, R.D., Lanna, E.A.T., Donzele, J.L., Matta, S.L.P. e Souza, M.A. 2007. Níveis de energia digestível da dieta sobre o desempenho de piauçu (Leporinus macrocephalus) em fase pós-larval. Acta Sci. Anim. Sci., 29: 109-114.

Navarro, R.D., Ribeiro Filho, O.P., Ferreira, W.M.e Pereira, F.K.S. 2009. A importância da vitamina E, C e A na reprodução de peixes: revisão de literatura. Rev. Bras. Reprod. Anim., 33: 20-25.

NRC. 1993. National Research Council. Nutrient requirements of fish. National Academy of Science. Washington, D.C. 105 pp.

Paula, T.A.R. 1999. Avaliação histológica e funcional do testículo de capivaras adultas (Hydrochoerus hydrochaeris). Tese (Doutorado em Morfologia). Instituto de Ciências Biológicas Universidade Federal de Minas Gerais. Belo Horizonte. 84 pp.

Rostagno, H.S., Albino, L.F.T., Donzele, J.L., Gomes, P.C., Ferreira, A.S., Oliveira, R.F. e Lopes, D.C. 2000. Tabelas brasileiras para aves e suínos. Composição de alimentos e exigências nutricionais. Universidade Federal de Viçosa-MG. Brasil. 114 pp.

Russell, L.D., França, L.R. and Hess, R. 1995. Characteristics of mitotic cells in developing and adult testes with observations on cell lineages. Tissue Cell, 27: 105-128.

Russell, L.D. 1996. Mammalian Leydig cell structure. In: Payne, A.H., Hardy, M.P. Russel, L.D. (eds.). The Leydig cell. Cache River Press. Vienna. pp. 43-96.

SAS. 1997. SAS User's Guide. Version 6. $4^{\mathrm{a}}$ edition. SAS Institute INC. North Caroline. 1686 pp. Sampaio, F.G., Kleemann, G.K., Sá, M.V.C. , Pereira, A.S., Barros, M.M. e Pezzato, L.E. 2004. Níveis de vitamina $E$ e de selênio para pós-larvas de Macrobrachium mazonicum. Acta Sc. Anim. Sci., 26: 129-135.

Tan, Q.R. and He, S.X. 1998. Effect of dietary supplementation of vitamins $A, D_{3}, E$, and $C$ on yearling rice field eel, Monopterus albus: serum indices, gonad development, and metabolism of calcium and phosphorus. J. World Aquacult. Soc., 29: 432-440.

Vilela, D.A.R. 2003. Duração da espermatogênese e proliferação das células de Sertoli em tilápiasnilóticas (Oreochromis niloticus) mantidas em diferentes temperaturas. Dissertação (mestrado). Universidade Federal de Minas Gerais. Belo horizonte. $54 \mathrm{pp}$.

Archivos de zootecnia vol. 59, núm. 228, p. 528. 